\title{
FEASIBILITY STUDIES OF THE THREE-WAVELENGTH MIE- SCATTERING POLARIZATION SCHEIMPFLUG LIDAR TECHNIQUE
}

\author{
Zheng Kong ${ }^{1}$, Teng Ma ${ }^{1}$, Zhenfeng Gong ${ }^{1}$, Kun Liu ${ }^{1}$, Liang Mei ${ }^{1, ~ *}$ \\ ${ }^{I}$ School of Optoelectronic Engineering and Instrumentation Science, Dalian University of Technology, \\ Dalian 116024, China \\ *Email: meiliang@dlut.edu.cn
}

\begin{abstract}
A three-wavelength Mie-scattering polarization Scheimpflug lidar system, utilizing 808-nm, 520$\mathrm{nm}$ and $405-\mathrm{nm}$ multimode laser diodes as light sources and two CMOS sensors as detectors, is developed for the studies of the aerosol extinction coefficient, depolarization ratio and the Ångström exponent. Atmospheric monitoring has been carried out on a near horizontal path from 23:00 January $14^{\text {th }}$ to $06: 00$ January $15^{\text {th }}, 2019$ at Dalian, which is a coast city in Northern China. By studying the depolarization, aerosol extinction coefficient and Ångström exponent, it has been found out that a strong north wind blew away local spherical haze particles and brought external non-spherical large-size particles. The measurement results indicated a promising future of employing the present three-wavelength polarization Scheimpflug lidar system in the applications of atmospheric remote sensing.
\end{abstract}

Keywords: Three-wavelength, Scheimpflug lidar, laser diode, aerosol, polarization, remote sensing.

\section{INTRODUCTION}

Mie-scattering atmospheric lidar is a very useful remote sensing tool and has been extensively used to investigate clouds, aerosol and boundary layer for decades. The conventional lidar technique is mainly based on the principle of photon time of flight, measuring the atmospheric backscattering signal of the transmitted laser pulse according to the time-of-arrival. The most common laser source used in the pulsed lidar systems is the $\mathrm{Nd}$ :YAG laser, which has a fundamental emission at $1064 \mathrm{~nm}$ and can be frequency doubled and tripled to $532 \mathrm{~nm}$ and $355 \mathrm{~nm}$, respectively [1-3]. The recently developed Scheimpflug lidar (SLidar) technique has also shown a great potential in the applications of atmospheric remote sensing [4-6]. The Scheimpflug principle reveals that the laser beam transmitted into atmosphere can be infocused on a tilted image sensor while employing a large-aperture telescope. In the present work, we developed a three-wavelength Mie-scattering polarization Scheimpflug lidar system based on 405-nm, 520-nm and 808-nm high-power continuous-wave laser diodes and two CMOS cameras. Atmospheric measurements have been performed to investigate the performance and feasibility of the lidar system in the applications of atmospheric aerosol monitoring in Dalian, which is a coast city in Northern China.

\section{EXPERIMENTAL SYSTEM}

The schematic of the three-wavelength Miescattering polarization SLidar system is shown in Fig. 1. Two 808-nm laser diodes, a 405-nm laser diode and a $520-\mathrm{nm}$ laser diode were used as light sources. Each laser diode was mounted on a copper sheet with a thermoelectric cooler to control the temperature.

The depolarization ratio measurement was achieved based on a time-multiplexing detection scheme, by employing two 808-nm laser diodes (LD I, LD II) with the same polarization states as light sources and a single CMOS camera as the detector. A half-wave plate was used to rotate the plane of polarization of LD II by $90^{\circ}$. The two orthogonal polarized 808-nm laser beams were combined by a polarization beam-splitter cube. A photodetector was utilized to monitor the intensities of residual beams, in order to monitor the variation of the two 808-nm diode lasers.

As laser beams emitted by the $405-\mathrm{nm}$ and 520-nm laser diodes (LD III and LD IV) have much larger divergences, a F6 lens will truncate the laser beam significantly, leading to a very low geometrical transmission efficiency of about $25 \%$. Thus, a cylindrical lens pair was designed to reduce the divergence along the fast axis and placed in front of the $405-\mathrm{nm}$ and the $520-\mathrm{nm}$ laser diode to improve the transmission efficiency $[7,8]$. The 405-nm and 520-nm laser beams were first combined by a dichroic mirror and then coupled together with the 808-nm laser beams. 
The joint laser beams were reflected by an elliptical mirror and then transmitted into the atmosphere through a F6 refractor. Each laser diode was mounted on an $x-y-z$ linear stage for focal and position adjustments.

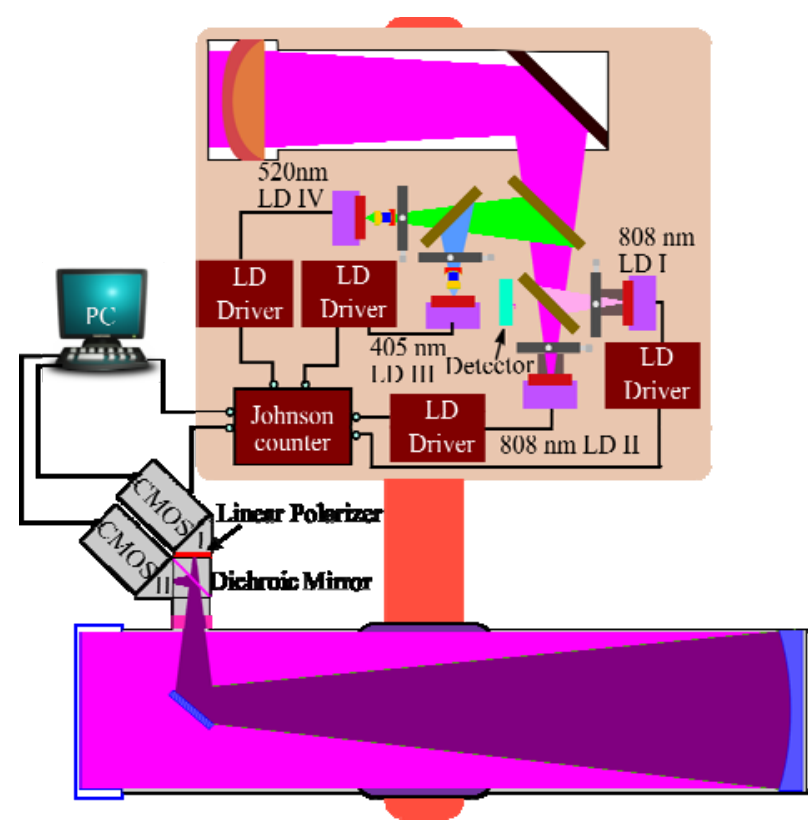

Fig. 1. Schematic of the three-wavelength Mie-scattering polarization Scheimpflug lidar system. LD I: $808 \mathrm{~nm}, 4 \mathrm{~W}$; LD II: $808 \mathrm{~nm}, 4 \mathrm{~W}$; LD III: $405 \mathrm{~nm}, 0.6 \mathrm{~W}$; LD IV:520 nm, $1 \mathrm{~W}$; Laser diode collimator: $\mathrm{f}=600 \mathrm{~mm}, \varnothing 104 \mathrm{~mm}$; Newtonian receiver: $\mathrm{F} 4, f=800 \mathrm{~mm}, \varnothing 200 \mathrm{~mm}$; Separation between the receiver and the collimator is about $806 \mathrm{~mm}$, the tilt angle of the CMOS sensor is $45^{\circ}$.

The backscattering signals were collected by a Newtonian telescope and detected by two $45^{\circ}$ tilted CMOS cameras. The short-wavelength backscattering signals (405 $\mathrm{nm}$ and $520 \mathrm{~nm}$ ) were separated from the near infrared signals by a dichroic mirror. The CMOS camera I was employed to detect the $808-\mathrm{nm}$ parallel and perpendicular polarized backscattering signals based on a time-multiplexing detection scheme [9]. A linear polarizer, with the polarization axis parallel to the polarization state of LD I, is mounted in front of the CMOS camera I. As the two 808-nm laser diodes are turned on and off sequentially, the CMOS camera I is able to detect the parallel and perpendicular polarized backscattering signals successively. A dark frame was also acquired, when the two laser diodes were both turned off, to eliminate background signals. The CMOS II camera detected the 405-nm and $520-\mathrm{nm}$ backscattering signals based on the timemultiplexing detection scheme.
The raw lidar signals were obtained by performing vertical pixel binning, background subtraction and median averaging. The total measurement time for all lidar curves is 1 minute, when performing 100-time signal averaging with 200-ms exposure time.

\section{MEASUREMENT AND RESULTS}

The three-wavelength polarization SLidar system was placed on the $8^{\text {th }}$ floor of the Graduate School of Education Building, Dalian University of Technology (DLUT) and the laser beam was about 27-m height above the outside ground. The lidar system was pointed to the south direction on a near horizontal path. Since no interference filters have been employed to suppress the sunlight background, the lidar system is only able to operate during nighttime. Thus, the measurement campaign was carried out from 23:00 January $14^{\text {th }}$ to 06:00 January $15^{\text {th }}, 2019$ in Dalian, China $\left(38.886^{\circ} \mathrm{N}, 121.532^{\circ} \mathrm{E}\right)$.
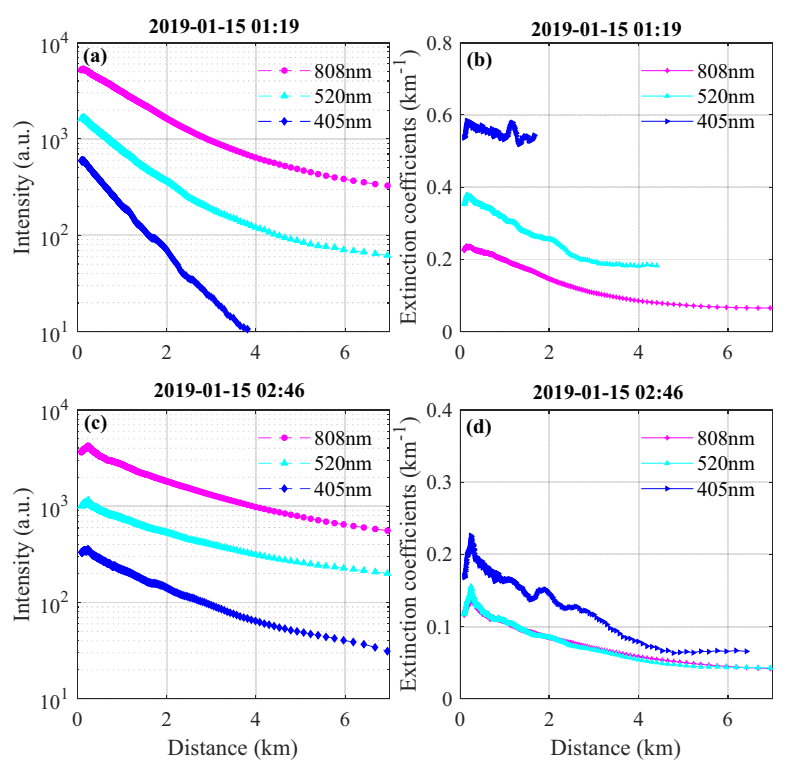

Fig. 2. (a) Atmospheric backscattering signals and (b) the aerosol extinction coefficients measured at $01: 19$ on January $15^{\text {th }}, 2019$; (c) Atmospheric backscattering signals and (d) the aerosol extinction coefficients measured at 02:46 on January $15^{\text {th }} 2019$.

The backscattering signals measured under two typical atmospheric conditions as well as the corresponding aerosol extinction coefficient retrieved based on the Fernald method are shown in Fig. 1 [10]. The lidar ratios for $808 \mathrm{~nm}, 520 \mathrm{~nm}$ and $405 \mathrm{~nm}$ are set to $40 \mathrm{sr}, 50 \mathrm{sr}$ and $50 \mathrm{sr}$, respectively [11-14]. Fig. 1 (a) and (b) were 
obtained during the haze while Fig. 1 (c) and (d) were acquired when the haze has been dissipated. Among all the backscattering signals, the 808-nm channel had the strongest intensity while the 405$\mathrm{nm}$ channel was the weakest one, mainly attributed to the power differences of laser diodes. In the meanwhile, the atmospheric extinction coefficient was generally larger in short wavelengths. Figure 3 shows the space-time evolution of the extinction coefficient at $808 \mathrm{~nm}$, which clearly illustrated the whole process of the transportation and the dissipation of the haze.

The depolarization ratio $\delta(z)$ is given by

$$
\delta(z)=k \frac{P_{s}(z)}{P_{p}(z)}
$$

Here $k$ is a polarization-dependent system constant of the lidar system and its value was 1.02 , calibrated by measuring backscattering signals without the linear polarizer. $P_{s}(z)$ and $P_{p}(z)$ are the s- and p-polarized lidar signals detected by the polarization Scheimpflug lidar system.

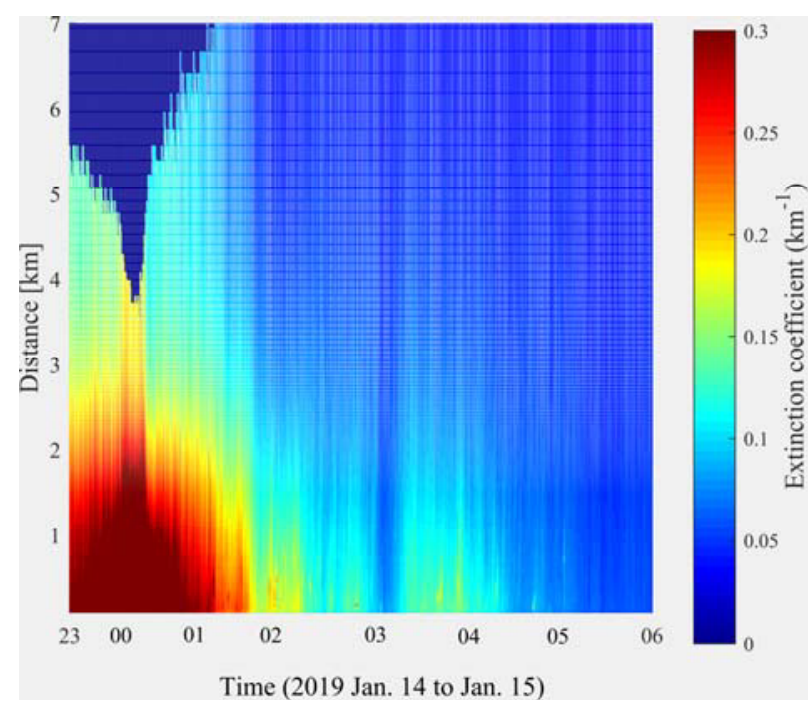

Fig. 3. Time-range map of aerosol extinction coefficients retrieved by the Fernald method at $808 \mathrm{~nm}$.

The time-space map of the depolarization ratio is shown in Fig. 4. The spatial variation of the depolarization ratio was not significant since it was measured on a near horizontal path, but the temporal change was obvious. The Ångström exponent, often used as a qualitative indicator of aerosol particle size [15-17], is also evaluated based on the lidar signals measured at $808 \mathrm{~nm}$ and $520 \mathrm{~nm}$. The spatial-temporal variation of the Ångström exponent is shown in Fig. 5.
According to the space-time variation of the 808-nm extinction coefficient, a severe haze can be clearly observed during 23:00 January $14^{\text {th }}$ to 01:20 January $15^{\text {th }}$. The PM2.5 and PM10 concentrations were up to $90 \mu \mathrm{g} / \mathrm{m}^{3}$ and 148 $\mu \mathrm{g} / \mathrm{m}^{3}$, respectively, reported by the Qixianling national pollution monitoring station. The RH was larger than $70 \%$. The depolarization ratio was $0.09 \pm 0.02$ and the Ångström exponent was about 1.0 .

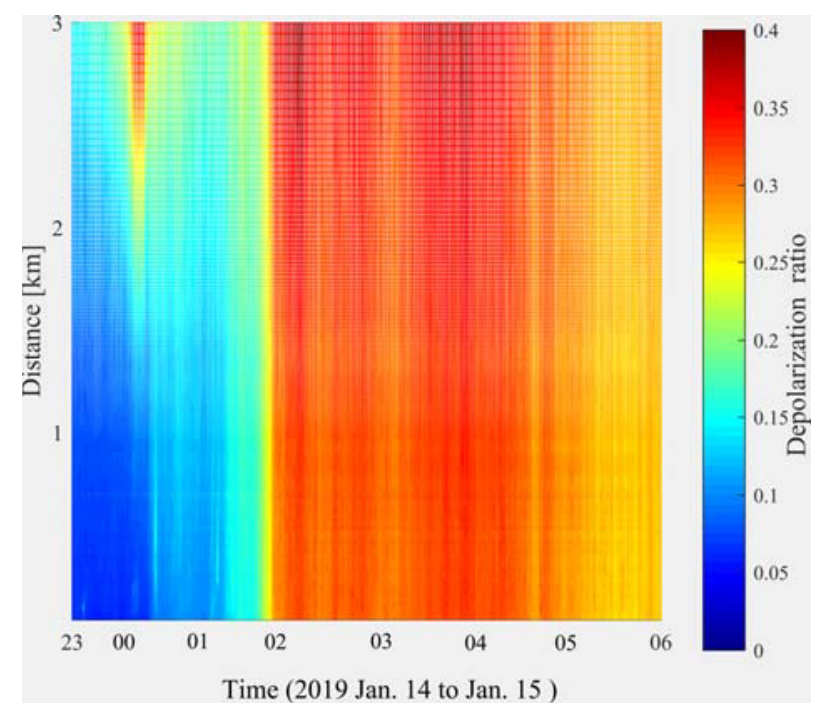

Fig. 4. Time-range map of depolarization ratio.

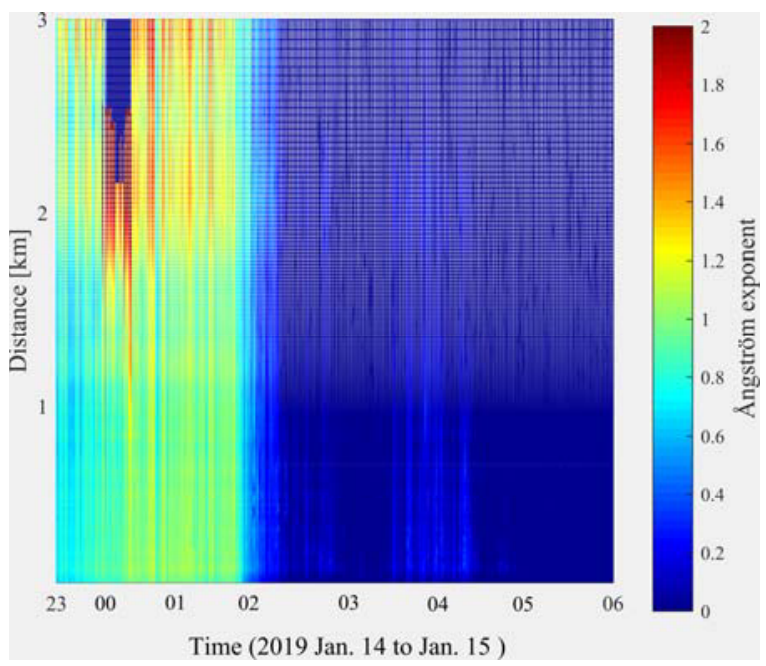

Fig. 5. Time-range map of the Ångström exponent at $808 \mathrm{~nm}$ and 520 $\mathrm{nm}$.

From 01:20 January $15^{\text {th }}$ to 02:00 January $15^{\text {th }}$, the local haze started to dissipate while the external pollution appeared due to the strong north wind. Correspondingly, the value of the extinction 
coefficient was decreasing, the depolarization ratio increased from 0.1 to 0.3 and the Ångström exponent decreased from 1.0 to 0 , which implied that the relative concentration of spherical particles gradually decreased and the atmosphere was dominated by non-spherical large-size dust particles [18-22]. During 02:00 to 06:00 on January $15^{\text {th }}$, the concentration of PM10 was beyond $100 \mu \mathrm{g} / \mathrm{m}^{3}$ and the concentration of PM2.5 drops to below $20 \mu \mathrm{g} / \mathrm{m}^{3}$, indicating that large-size particles dominated the atmosphere, which was in good agreement with the Ångström exponent.

\section{CONCLUSION}

This work has developed a three-wavelength polarization Scheimpflug lidar system for atmospheric remote sensing by employing four high-power continuous-wave multimode laser diodes as the laser sources and two CMOS sensors as the detectors. Atmospheric measurements have been performed from 23:00 January $14^{\text {th }}$ to $06: 00$ January $15^{\text {th }}, 2019$. The dissipation of local haze and the occurrence of dust particles due to external transportation have been evaluated based on the extinction coefficient, depolarization ratio, Ångström exponent as well as other atmospheric parameters. During this period, the depolarization ratio increased from 0.1 to 0.3 and the Ångström exponent decreased from 1 to nearly zero. The PM10 concentration was always beyond 100 $\mu \mathrm{g} / \mathrm{m}^{3}$, while the PM2.5 concentration decreased from $90 \mu \mathrm{g} / \mathrm{m}^{3}$ to $20 \mu \mathrm{g} / \mathrm{m}^{3}$ due to the strong north wind, which blew away local spherical haze particles and brought external non-spherical largesize particles. Experimental measurements are planned in the near future for in-depth studies of the system performance as well as application explorations.

\section{ACKNOWLEDGEMENTS}

This work was supported by National Key Research and Development Program of China (2016YFC0200600); National Natural Science Foundation of China (61705030); Natural Science Foundation of Liaoning Province, China (201602163); Fundamental Research Funds for the Central Universities (DUT18JC22).

\section{REFERENCES}

1. Y. Mabuchi, N. Manago, G. Bagtasa, H. Saitoh, N. Takeuchi, M. Yabuki, T. Shiina, and H. Kuze, 2012 Ieee International Geoscience and Remote Sensing Symposium (Igarss), 2505-2508 (2012).

2. J. F. Shao and J. D. Mao, Aopc 2015: Optical and Optoelectronic Sensing and Imaging Technology 9674, (2015).

3. Y. Hara, T. Nishizawa, N. Sugimoto, K. Osada, K. Yumimoto, I. Uno, R. Kudo, and H. Ishimoto, Remote Sens-Basel 10, 937 (2018).

4. L. Mei, P. Guan, and Z. Kong, Opt. Express 25, A953-A962 (2017).

5. L. Mei and M. Brydegaard, Opt. Express 23, 16131628 (2015).

6. G. D. Sun, L. A. Qin, Z. H. Hou, X. Jing, F. He, F. F. Tan, and S. L. Zhang, Opt. Express 26, 7423-7436 (2018).

7. L. Mei, P. Guan, Y. Yang, and Z. Kong, Opt. Express 25, A628-A638 (2017).

8. L. Mei, Z. Kong, and P. Guan, Opt. Express 26, A260-A274 (2018).

9. L. Mei and P. Guan, Opt. Lett. 42, 3562-3565 (2017).

10. F. G. Fernald, Appl. Opt. 23, 652-653 (1984).

11. J. Su, Z. Y. Liu, Y. H. Wu, M. P. McCormick, and L. Q. Lei, Atmos. Environ. 79, 36-40 (2013).

12. C. Cordoba-Jabonero, J. A. Adame, J. R. Campbell, E. Cuevas, J. P. Diaz, F. Exposito, and M. Gil-Ojeda, EPJ Web Conf. 119, (2016).

13. H. Z. Ji, Y. C. Zhang, S. Y. Chen, H. Chen, and P. Guo, Opt. Commun. 416, 54-60 (2018).

14. H. Zhao, J. D. Mao, C. Y. Zhou, and X. Gong, J. Quant. Spectrosc. \& Rad. Transf. 217, 224-228 (2018).

15. G. L. Schuster, O. Dubovik, and B. N. Holben, J. Geophys. Res. - Atmos. 111, (2006).

16. N. G. Loeb and G. L. Schuster, J. Geophys. Res. Atmos. 113, (2008).

17. H. Moosmuller, R. K. Chakrabarty, K. M. Ehlers, and W. P. Arnott, Atmos. Chem. Phys. 11, 1217-1225 (2011).

18. S. Shin, D. Muller, Y. J. Kim, B. Tatarov, D. Shin, P. Seifert, and Y. M. Noh, Asia-Pac J Atmos Sci 49, 19-25 (2013).

19. Y. Song, B. Zhang, G. Shi, S. Li, H. Di, Q. Yan, and D. Hua, Particuology 40, 62-69 (2018).

20. Y. Noh, D. Muller, K. Lee, K. Kim, K. Lee, A. Shimizu, S. W. Kim, I. Sano, and C. B. Park, Atmos. Chem. Phys. 17, 6271-6290 (2017).

21. G. Y. Dai, S. H. Wu, and X. Q. Song, Remote Sens-Basel 10, 378 (2018).

22. M. Haarig, A. Ansmann, H. Baars, C. Jimenez, I. Veselovskii, R. Engelmann, and D. Althausen, Atmos. Chem. Phys. 18, 11847-11861 (2018). 